\title{
Molecular Characterization of Nitroimidazole Resistance in Metronidazole-Resistant Bacteroides Species Isolated from Hospital Patients in Kuwait
}

\author{
Wafaa Y. Jamala V.O. Rotimi ${ }^{a}$ J.S. Brazierc Molly Johny ${ }^{b}$ \\ Wafaa M. Wetieh ${ }^{b}$ B.I. Duerden ${ }^{c}$ \\ aDepartment of Microbiology, Faculty of Medicine, Kuwait University/Mubarak Al-Kabeer Hospital, Jabriya, and \\ ${ }^{b}$ Division of Microbiology, Al-Amiri Hospital, Kuwait; ${ }^{c P H L S}$ Anaerobe Reference Unit, \\ Department of Medical Microbiology and PHL, University Hospital of Wales, Cardiff, UK
}

\author{
Key Words \\ Bacteroides spp. · Metronidazole resistance $\cdot \mathrm{Nim}$ \\ genes $\cdot$ Hospital patients, Kuwait
}

\begin{abstract}
Objectives: The aim of this study was to screen for infections caused by metronidazole (MTZ)-resistant Bacteroides spp., and to characterize the genes that encode the MTZ resistance. Materials and Methods: A total of 7 MTZ-resistant Bacteroides spp. were isolated from 5 patients with MTZ-resistant infections. These organisms were investigated for carriage of genes that encode MTZ resistance. The presence of these genes was investigated by PCR and the PCR products were subjected to PCR-RFLP analysis. Results: The strains were MTZ-resistant with minimum inhibitory concentrations of $>32 \mu \mathrm{g} /$ $\mathrm{ml}$. The presence of nim genes was indicated by PCR in all 7 strains. PCR-RFLP analysis of the nim gene products demonstrated two of the five reported resistance genes, $\operatorname{nimA}-\operatorname{nim} \mathrm{E}$. These two resistance genes were nimE in 5 of the 7 isolates and nimA in 2 strains. Conclusion: MTZresistant Bacteroides spp. have been isolated from patients in Kuwait. Nim genes, specifically nimE and $\operatorname{nimA}$, mediate the drug resistance in these isolates. The meth-
\end{abstract}

\section{KARGER}

Fax +41613061234

E-Mail karger@karger.ch

www. karger.com
(C) 2004 S. Karger AG, Basel

1011-7571/04/0133-0147\$21.00/0

Accessible online at:

www. karger.com/mpp ods used in detecting these genes are rapid, accurate and relatively inexpensive and could be adopted easily to help in monitoring emergence of MTZ resistance determinants in Kuwait.

Copyright $@ 2004$ S. Karger AG, Basel

\section{Introduction}

Bacteroides spp. are gram-negative non-sporing anaerobic bacilli that form part of the normal human colonic microflora. The species most often isolated from faecal flora are Bacteroides vulgatus, Bacteroides thetaiotaomicron, Bacteroides distasonis and, to a lesser extent, Bacteroides fragilis and Bacteroides ovatus [1, 2]. These organisms cause opportunistic infections in a wide range of sites such as intra-abdominal infections, perirectal abscess, blood and soft tissue infections [3-5]. Over the last three decades, metronidazole (MTZ) has remained the main therapy of choice and it has been used extensively in prophylaxis and therapy of infections due to Bacteroides spp., because Bacteroides have been predictably sensitive, and because strains of this genus are often resistant to the main clinically relevant antibiotics, such as $\beta$-lactam antibiotics, tetracycline or macrolides-lincosamides-strepto-
Prof. V.O. Rotimi

Department of Microbiology

Faculty of Medicine, Kuwait University

PO Box 24923, 13110 Safat (Kuwait)

Tel./Fax+965 53327 19, E-Mail vincent@hsc.kuniv.edu.kw 
gramins [6]. In addition, other groups of anaerobes that are involved in the above infection sites are usually susceptible to MTZ.

However, despite the global use of MTZ, only sporadic case reports of MTZ-resistant Bacteroides spp. have appeared since 1978 [7-12]. These reports underscore the fact that laboratories which rely solely upon MTZ sensitivity to identify the presence of anaerobe in primary cultures from clinical specimens must be vigilant [13], because of the possibility of underreporting MTZ-resistant anaerobes. Detection of 5-nitroimidazole-resistant strains by conventional disc susceptibility testing methods requires conditions of strict anaerobiosis because of pseudoresistance in the presence of even low levels of oxygen [14-16], which may lead to reporting of false MTZ-resistant strains.

A review by Reysset [17], on the genetics of 5-nitroimidazole resistance in Bacteroides spp., has highlighted a number of possible MTZ resistance mechanisms. However, mounting evidence shows that some MTZ-resistant strains possess specific nitroimidazole-resistant genes, nim genes, which have been characterized as nimA$\operatorname{nim} \mathrm{E}[17-20]$. These genes are believed to encode a nitroimidazole reductase that converts 4- or 5-nitroimidazole to 4- or 5-aminoimidazole, thus avoiding the formation of toxic nitroso radicals that are essential for antimicrobial activity [21].

The aim of this study was to isolate MTZ-resistant Bacteroides spp. from hospitalized patients in Kuwait and to characterize the resistance determinants in these strains.

\section{Materials and Methods}

\section{Patients}

\section{Case 1}

A 46-year-old Pakistani driver was admitted to hospital because of colicky abdominal pain of 2 days' duration that was localized to the right iliac fossa (RIF), together with nausea and vomiting. On examination, he was in pain, febrile $\left(38.4^{\circ} \mathrm{C}\right)$, and had guarding and rebound tenderness over the RIF. Haematological investigation showed leucocytosis with WBC count of $30,000 / \mathrm{mm}^{3}$ (mainly polymorphs with shift to the left). A diagnosis of acute appendicitis was made and the patient was prepared for emergency surgery. At laparotomy, there was moderate peritoneal reaction with a gangrenous and retrocaecally located appendix. An appendicectomy was performed. At this time, a peritoneal swab was taken for culture. MTZ $500 \mathrm{mg}$ intravenous (i.v.) every $8 \mathrm{~h}$ and cefuroxime $750 \mathrm{mg}$, i.v., every $8 \mathrm{~h}$, were given perioperatively and continued for 7 days. His postoperative period featured a variety of complications including fever (temperature, $38-38.5^{\circ} \mathrm{C}$ ) and diarrhoea that started on the 4 th postoperative day. Blood culture was negative and the stool culture yielded no known enteric pathogen. However, culture of the peritoneal swab yielded a mixed growth of (i) microaerophilic streptococci, (ii) $\alpha$-haemolytic streptococci, and (iii) $B$. fragilis resistant to MTZ and clindamycin, but sensitive to cefoxitin and piperacillin. MTZ was removed from the antibiotic regimen and meropenem was substituted. Subsequently he made good recovery and was discharged home 15 days after admission. The patient denied taking MTZ prior to admission to the hospital.

\section{Case 2}

A 33-year-old Indian housemaid was admitted to hospital with the complaints of right lower abdominal pain of 10 days' duration, nausea, vomiting and diarrhoea of 1 day duration. On examination, she was found to be underweight $(40 \mathrm{~kg})$, dehydrated and obviously in pain. She was febrile (temperature, $38.3{ }^{\circ} \mathrm{C}$ ). The abdomen was tender and tense on the right lower quadrant with rebound tenderness over the RIF. Bowel sounds were reduced but no mass was felt. Erect abdominal X-ray showed fluid level at the right lower part of the bowel. All other systems were normal. Initial haematological investigations revealed leucocytosis (WBC count of $22,400 / \mathrm{mm}^{3}$, with mild left shift and band formation), anaemia ( $\mathrm{Hb}$ of $7.2 \mathrm{~g} / \mathrm{dl}$ with hypochromic, monocytic anaemia) and high platelet count $\left(579,000 / \mathrm{mm}^{3}\right)$. She was transfused with 4 units of blood and 2 days later a salpingo-oophorectomy was performed. During manipulation of the mass, the sigmoid colon was inadvertently perforated and was repaired during the operation. Tissue was sent for histopathological examination.

Postoperatively, she was placed on a ceftriaxone, i.v., $1 \mathrm{~g}$ once daily (o.d.) and MTZ, i.v., $500 \mathrm{mg}$ every $8 \mathrm{~h}$, regimen for 7 days. Recovery was stormy but she was able to open her bowel and took oral fluids after 5 days on i.v. fluids.

Histopathology of the tissue revealed tuberculous salpingo-oophoritis. Her antibiotics were stopped and she was started on four antituberculous drugs, isoniazid $200 \mathrm{mg}$, o.d., rifampicin $450 \mathrm{mg}$ o.d., ethambutol $1.125 \mathrm{~g}$ o.d. and pyrazinamide, $40 \mathrm{mg}$ o.d. She made good progress and was discharged home 18 days after admission.

However, 22 days after discharge, she was readmitted because of painful swelling of 3 days' duration in the abdominal wall, in the RIF, which increased with time. It was not associated with fever, vomiting or change in the bowel motion.

She was started on a cocktail of antibiotics including ceftriaxone, i.v., 1 g o.d. for 9 days, MTZ, i.v., $500 \mathrm{mg}$ every $8 \mathrm{~h}$ for 9 days and amikacin $500 \mathrm{mg}$ every $12 \mathrm{~h}$ for 7 days, in addition to her antituberculous drugs. Ultrasound and CT scan of the abdomen revealed multiple small foci of pus collection in the abdominal wall and RIF. The abscess was incised and drained and a sample of pus sent to the microbiology laboratory. Culture of the pus yielded a mixed growth of (i) Escherichia coli, (ii) Enterococcus spp., and (iii) B. fragilis resistant to MTZ. The therapy was then changed to ampicillin, $500 \mathrm{mg}$ every $6 \mathrm{~h}$ and meropenem, 1 g every $8 \mathrm{~h}$. After 26 days in the hospital the patient was discharged home with a follow-up appointment at the surgical outpatient and TB clinic. However, she did not appear at the follow-up.

\section{Cases 3, 4 and 5}

These patients were from Mubarak Al-Kabeer Teaching Hospital, Kuwait as reported previously by Rotimi et al. [12]. They were the first documented cases of infection caused by MTZ-resistant Bacteroides spp. in Kuwait. 


\section{Bacterial Strains}

A total of 7 MTZ-resistant Bacteroides isolates from these 5 patients were used in this study for the characterization of resistance determinants. These isolates comprised $4 \mathrm{~B}$. fragilis (designated 957 from case 1, 961 from case 2, 329 from case 3 , and 338 a from case 4 ), $1 \mathrm{~B}$. distasonis ( 457 a from case 5 ), $1 \mathrm{~B}$. ovatus ( $338 \mathrm{~b}$ from case 4 ) and $1 \mathrm{~B}$. thetaiotaomicron $(457 \mathrm{~b}$ from case 5 ). Isolates were cultured on fastidious anaerobe agar (FAA; Lab M, Bury, UK) supplemented with $5 \%(\mathrm{vol} / \mathrm{vol})$ horse blood in an anaerobic atmosphere $\left(10 \% \mathrm{CO}_{2}\right.$, $10 \% \mathrm{H}_{2}$ in $80 \% \mathrm{~N}_{2}$ ) at $37^{\circ} \mathrm{C}$. All strains were identified to species level by conventional tests and API 20A (bioMerieux, France) in the Anaerobe Laboratory, Department of Microbiology, Faculty of Medicine/Mubarak Al-Kabeer Hospital, Kuwait. Five positive control strains containing nim genes, B. fragilis $\mathrm{BF} 8(\operatorname{nim} \mathrm{B}), B$. fragilis $638 \mathrm{R}$ containing plasmid pIP417 (nimA), B. fragilis 638R containing plasmid pI419 (nimC), B. fragilis 638R containing plasmid pIP421 (nimD) and B. fragilis ARU $6881(\operatorname{nim} \mathrm{E})$, were obtained from the PHLS Anaerobe Reference Unit, University Hospital of Wales, Cardiff, UK.

\section{Susceptibility Testing}

All the Bacteroides isolates exhibited no zone to a 5- $\mu \mathrm{g}$ MTZ disc. The quantitative minimum inhibitory concentration (MIC) of MTZ was determined by E-test strips (AB Biodisk, Solna, Sweden) on FAA, according to the manufacturer's instructions.

\section{Nim Gene PCR}

The presence of nim genes in the isolates which exhibited resistance to MTZ was assessed by PCR, using a method described previously [20] with minor modifications. Briefly, a single colony, harvested after culture for $18 \mathrm{~h}$ on FAA, was suspended in $100 \mu \mathrm{l}$ of $5 \%$ Chelex 100 (BioRad Laboratories, USA) and heated for $12 \mathrm{~min}$ at $100^{\circ} \mathrm{C}$. The cell suspension was centrifuged for $10 \mathrm{~min}$ at $17,000 \mathrm{~g}$ to remove the cell debris. The supernatant was used as DNA template.

The nim genes were amplified with the primers NIM-3 (5'-ATG TTC AGA GAA ATG CGG CGT AAG CG-3') and NIM-5 (5'-GCT TCC TTG CCT GTC ATG TGC TC-3').

DNA amplification was performed in $50 \mu \mathrm{l}$ of reaction mixture containing $200 \mu M$ of each deoxynucleoside triphosphate, $1 \mu M$ of each primer, $5 \mu \mathrm{l}$ PCR buffer $(10 \mathrm{~m} M$ Tris- $\mathrm{HCl}, 50 \mathrm{mM} \mathrm{KCl}, 1.5 \mathrm{~m} M$ $\mathrm{MgCl}_{2}, 0.1 \%$ Triton X-100, $0.2 \mathrm{mg}$ bovine serum albumin or gelatin/ $\mathrm{ml}, \mathrm{pH}$ 9), $35.8 \mu \mathrm{l}$ distilled water, $0.2 \mu \mathrm{l}$ of Taq polymerase (Promega, Madison, Wisc., USA) and $5 \mu$ of DNA sample. A water blank with no template was included in the run as a negative control. The target DNA was amplified in a thermal cycler (model Crocodile III; Appligene Oncor). After an initial denaturation step at $95^{\circ} \mathrm{C}$ for $3 \mathrm{~min}$, the reaction mixtures were subjected to 30 cycles of denaturation at $95^{\circ} \mathrm{C}$ for $45 \mathrm{~s}$, annealing at $52^{\circ} \mathrm{C}$ for $60 \mathrm{~s}$, extension at $72^{\circ} \mathrm{C}$ for $90 \mathrm{~s}$ and a final extension step at $72^{\circ} \mathrm{C}$ for $10 \mathrm{~min}$.

PCR products were resolved by electrophoresis on $1 \%$ agarose gel run in $1 \times$ TAE (0.04 $M$ Tris-acetate buffer, $1 \mathrm{~m} M$ EDTA, $\mathrm{pH} 8)$ at $60 \mathrm{~mA}$ for $45 \mathrm{~min}$ with a molecular weight standard $(100 \mathrm{bp}$; Advanced Biotechnologies, Epsom, UK). The gel was stained with ethidium bromide $(0.5 \mu \mathrm{g} / \mathrm{ml})$ and PCR products were visualized by UV light.

Restriction Enzyme Digests of nim Gene PCR Products

The method of Stubbs et al. [20] was followed for restriction fragment length polymorphism (RFLP) analysis. The amplification products from nim gene PCR were treated with the restriction endonucleases HpaII and TaqI (Promega), according to the manufacturer's instructions. Digestion products were resolved in Metaphor agarose $3 \%(\mathrm{w} / \mathrm{v}$, FMC Bioproducts) and run at $70 \mathrm{~mA}, 200 \mathrm{~V}$ in TAE for $3 \mathrm{~h}$. The gel was stained with ethidium bromide $(0.5 \mu \mathrm{g} / \mathrm{ml})$ and products visualized with UV light. The bands were compared with those from 5 positive controls that contained the five different nim genes, A-E.

\section{Results}

\section{Conventional Identification}

The 7 strains were all anaerobic gram-negative bacilli, non-sporing and non-motile. Biochemical and fermentation reactions by these strains enabled identification to species level. The $B$. fragilis strains typically were indolenegative, fermented melibiose, sucrose and glycogen but not arabinose, rhamnose, salicin, trehalose and xylan, and were $\alpha$-fucosidase-positive. The $B$. distasonis strain was indole-negative and $\alpha$-fucosidase-negative but fermented all the sugars except xylan whereas the B. ovatus strain was indole-positive, fermented all the sugars and was $\alpha$ fucosidase-positive. B. thetaiotaomicron was identified by being indole- and $\alpha$-fucosidase-positive, and fermenting all sugars except xylan. API 20A accurately identified all the strains to species level with $99.9 \%$ agreement.

\section{Nitroimidazole Resistance}

All the 7 clinical strains were resistant to MTZ by the disc diffusion test and by MIC determination with values $>32 \mu \mathrm{g} / \mathrm{ml}$. MTZ MIC values for $B$. fragilis control strains were: Bf- $8>32 \mu \mathrm{g} / \mathrm{ml}, 638 \mathrm{R}$ (pIP417) $24 \mu \mathrm{g} / \mathrm{ml}, 638 \mathrm{R}$ (pIP419) $6 \mu \mathrm{g} / \mathrm{ml}, 638 \mathrm{R}$ (pIP421) $16 \mu \mathrm{g} / \mathrm{ml}$ and ARU $6881>32 \mu \mathrm{g} / \mathrm{ml}$. The MTZ MIC value for the $B$. fragilissensitive control strain was $0.13 \mu \mathrm{g} / \mathrm{ml}$. As demonstrated in figure 1, all the 5 control strains containing the different nim genes gave visible PCR products (lanes 2-6) and the 7 clinical isolates also gave visible PCR products with the primers NIM-3 and NIM-5 (lanes 7-13), whereas a water blank did not (lane 14).

The 5 different nim gene PCR products from the control strains produced unique digestion profiles with $\mathrm{HpaII}$ and TaqI (fig. 2a, b), shown in lanes 2-6. PCR products from nim genes in the 7 clinical isolates (lanes 8-14) were identified by comparing the digestion patterns with those from the five $\mathrm{nim}$ genes of the control strains. The first 5 isolates from the first 4 patients carried $\operatorname{nim} \mathrm{E}$ genes, whereas the $B$. distasonis and $B$. thetaiotaomicron isolates from the last patient carried a $\operatorname{nim} \mathrm{A}$ gene.

Med Princ Pract 2004;13:147-152

Bacteroides spp. 


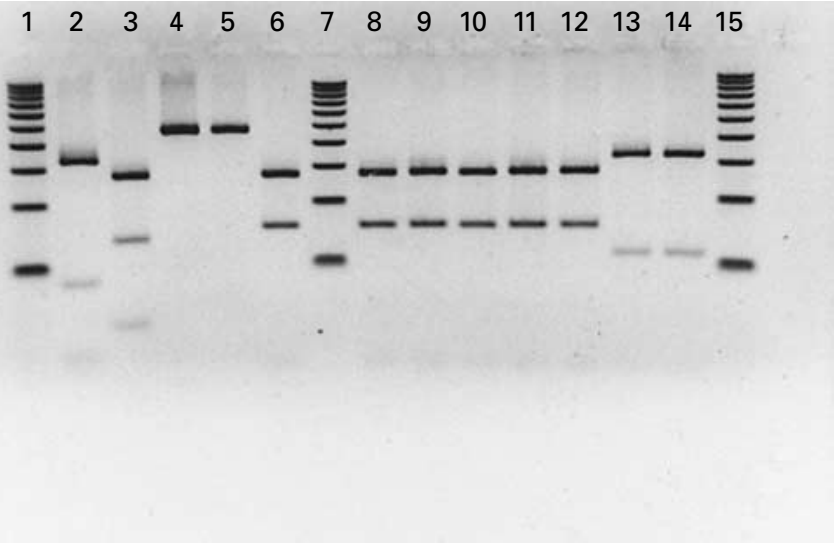

a

Fig. 1. PCR products of nim genes of Bacteroides spp.: lane1: 100-bp ladder; lane 2: nimA-positive control; lane 3: nimB-positive control; lane 4: nimC-positive control; lane 5: nimD-positive control; lane 6: nimE-positive control; lane 7: B. fragilis (No. 961); lane 8: B. fragilis (No. 957); lane 9: B. fragilis (No. 329); lane 10: B. fragilis (No. 388a); lane 11: B. ovatus (No. 388b); lane 12: B. distasonis (No. 457a); lane 13: B. thetaiotaomicron (No. 457b); lane 14: water blank.

\section{Discussion}

The 2 cases from the Amiri Hospital reported in this study had contrasting features. While the isolation of MTZ-resistant Bacteroides spp. was subsequent to MTZ therapy in the 2 nd patient, the 1st patient, whose peritoneal specimen was taken at laparotomy, before MTZ was given, also yielded MTZ-resistant $B$. fragilis although this 1st patient gave no history of MTZ use. Both isolates had MTZ MIC values of $>32 \mu \mathrm{g} / \mathrm{ml}$. Our previous report [12] showed that it was possible for short-term MTZ therapy to give rise to acquisition of resistance, contrary to previous reports $[7,10,11]$, but resistance in patients with no previous history of MTZ treatment is very rare [8]. Several mechanisms of MTZ resistance have been described in Bacteroides spp., including transferable resistance [22, 23]. The existence of transferable resistance in some strains supports the possibility of intra- and interspecies spread of MTZ resistance, which may explain how case 1 acquired the MTZ-resistant $B$. fragilis.

Bacteroides spp. are the anaerobes most frequently isolated from a variety of clinical materials. Unfortunately, most clinical microbiology laboratories still assume that only colonies with a zone of inhibition around a $5-\mu \mathrm{g}$ MTZ disc on solid media are obligate anaerobes [13]. This assumption overlooks the possibility of MTZ resistance in anaerobic organisms with a consequent underestimation

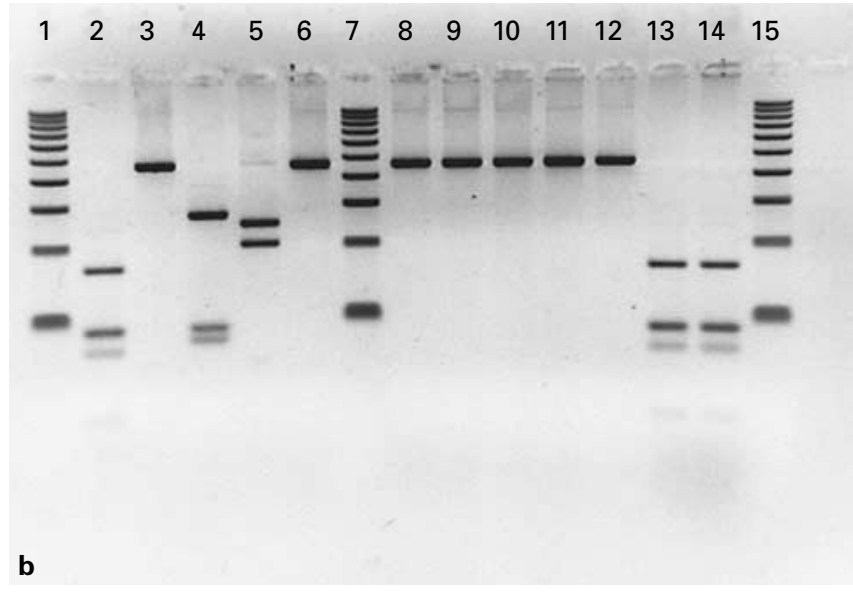

Fig. 2. a RFLP profile for HpaII restriction enzyme digest obtained with control strains of $\operatorname{nim} \mathrm{A}$ to $\operatorname{nim} \mathrm{E}$ genes (lane 2-6, respectively) and 7 other isolates. Lane 8: B. fragilis (No. 961); lane 9: B. fragilis (No. 957); lane 10: B. fragilis (No. 329); lane 11: B. fragilis (No. 338a); lane 12: B. ovatus (No. 388b); lane 13: B. distasonis (No. 457a); lane 14: B. thetaiotaomicron (No. 457b), and lanes 1, 7 and 15: 100-bp ladder. b RFLP profile for TaqI restriction enzyme digest obtained with control strains of $\operatorname{nimA}$ to $\operatorname{nim}$ E genes (lanes 2-6, respectively) and 7 other isolates. Lane 8: B. fragilis (No. 961); lane 9: B. fragilis (No. 957); lane 10: B. fragilis (No. 329); lane 11: B. fragilis (No. 338a); lane 12: B. ovatus (No. 388b); lane 13: B. distasonis (No. 457a); lane 14: B thetaiotaomicron (No. 457b), and lanes 1, 7 and 15: 100-bp ladder.

of anaerobic infections and underreporting of MTZ-resistant isolates. Reports have highlighted the emergence of MTZ-resistant Bacteroides spp. in France [24, 25]. A recent report of a case of treatment failure with MTZ regimen in Kuwait [12] underscores the importance of vigilance in the laboratory in order to promptly identify potential problems of MTZ-resistant isolates. It is therefore important that both laboratory staff and clinicians be 
Table 1. Location, species number, MICs of MTZ and nim gene type of Bacteroides isolates in Kuwait

\begin{tabular}{lllll}
\hline $\begin{array}{l}\text { Patient/ } \\
\text { lane No. }{ }^{1}\end{array}$ & Hospital & Species (strain No.) & $\begin{array}{l}\text { MTZ MIC } \\
\mu \mathrm{g} / \mathrm{ml}\end{array}$ & ${\text { Nim } \text { gene }^{2}}$ \\
\hline $1 / 8$ & Amiri & B. fragilis 961 & $>32$ & $\mathrm{E}$ \\
$2 / 9$ & Amiri & B. fragilis 957 & $>32$ & $\mathrm{E}$ \\
$3 / 10$ & Mubarak & B. fragilis 329 & $>32$ & $\mathrm{E}$ \\
$4 / 11$ & Mubarak & B. fragilis $388 a$ & $>32$ & $\mathrm{E}$ \\
$4 / 12$ & Mubarak & B. ovatus 388b & $>32$ & $\mathrm{E}$ \\
$5 / 13$ & Mubarak & B. distasonis 457a & $>32$ & $\mathrm{~A}$ \\
$5 / 14$ & Mubarak & B. thetaiotaomicron 457b & $>32$ & $\mathrm{~A}$ \\
\hline 1 & Lane number in figures 2a, b. & & \\
2 & Restriction enzyme digest (HpaII and TaqI) of nim gene PCR products. & \\
\hline
\end{tabular}

aware of the potential for encountering Bacteroides spp. that are resistant to MTZ and other antimicrobial agents $[12,17,25]$.

This is the first report of nim genes that encode MTZ resistance among clinical strains of Bacteroides spp. in Kuwait. The nim gene PCR product analysis showed that the 7 strains from the 5 patients contained nim genes. With the RFLP analysis of the PCR products, identification of the specific genes could be delineated. In this study, two types of nim genes were detected; 5 strains contained $\operatorname{nim} \mathrm{E}$ and the remaining 2 contained $\operatorname{nim} \mathrm{A}$. The $\operatorname{nim} \mathrm{A}, \operatorname{nim} \mathrm{C}$, and $\operatorname{nim} \mathrm{D}$ genes have been shown to be located on small plasmids, pIP417, pIP419 and pIP421, respectively, and appear to be associated with lower MICs of MTZ $[19,26]$, whereas $\operatorname{nim} \mathrm{B}$ and nimE are chromosomally located and tended to exhibit higher MTZ MICs $[18,20,26]$. NimE was present in 4 MTZ-resistant (MIC, $>32 \mu \mathrm{g} / \mathrm{ml}$ ) B. fragilis isolates and 1 B. ovatus. The nimA genes were found in the $B$. distasonis and $B$. thetaiotaomicron isolates with MTZ MICs of $>32 \mu \mathrm{g} / \mathrm{ml}$ each. Thus, it would appear that the nim genes are not specific to individual species, thereby suggesting that interspecies transfer of these genes may be common [20].

Although the numbers are small, $\operatorname{nim} \mathrm{E}$ appears to be the predominant gene encoding MTZ resistance in clinical Bacteroides isolates in Kuwait. No $\operatorname{nim} \mathrm{B}, \operatorname{nim} \mathrm{C}$ and $\operatorname{nim} \mathrm{D}$ were detected. This is in contrast to $\operatorname{nim} \mathrm{B}$ that is prevalent among the MTZ-resistant Bacteroides spp. isolated in Morocco [18] and South Africa [27] and nimA in a series from the UK [20].

It is tempting to speculate that the $4 \mathrm{~B}$. fragilis strains with the same $\operatorname{nim} \mathrm{E}$ gene which were isolated from 2 patients each in Amiri and Mubarak Hospitals might represent the same bacterial clone which had spread from one patient to the other. However, Bacteroides spp. are a group of non-sporing gram-negative obligate anaerobes that are members of the normal endogenous flora of the gut. Cross-infection or nosocomial spread of these organisms has not been described and the patients were in the hospitals at different times, which would make the possibility of nosocomial spread extremely remote.

In conclusion, 1 of the 2 patients described in detail in this study acquired MTZ-resistant $B$. fragilis without a history of previous exposure to MTZ. The present study has also demonstrated the occurrence of $\operatorname{nim} \mathrm{E}$ genes among Bacteroides spp. isolated in Kuwait and showed that the two nim genes probably encoded MTZ resistance in our isolates, a result concordant with previous reports by other groups. In addition, our results emphasize the need for continuous surveillance of antibiotic resistance in Bacteroides spp.

\section{Acknowledgement}

We gratefully acknowledge the help and technical support of Dr. M. Gal and Ms. May Shahin. 


\section{References}

1 Holdeman LV, Good IJ, Moore WE: Human faecal flora: Variation in bacterial composition within individuals and a possible effect of emotional stress. Appl Environ Microbiol 1976;31: 359-375.

2 Duerden BI: The isolation and identification Bacteroides spp. from the normal human faecal flora. J Med Microbiol 1980;13:69-78.

3 Brook I: Bacteroides infections in children. J Med Microbiol 1995;43:92-98.

4 Finegold SM: Anaerobic Bacteria in Human Disease. New York, Academic Press, 1977.

5 Panigrahi D, Rotimi VO, Dhar R, Chugh TD, Dhar PM, Ghali A, Saad A, Sanyal SC, Verghese TL: Anaerobic bacterial flora of intraabdominal infections and their antimicrobial susceptibility pattern in Kuwait. Anaerobe 2001;7:291-295.

6 Gracia-Rodriguez JA, Gracia-Sanchez JE, Munoz-Bellido JL: Antimicrobial resistance in anaerobic bacteria: Current situation. Anaerobe 1995;1:69-80.

7 Ingham HR, Eaton S, Venables CW, Adams PC: Bacteroides fragilis resistant to metronidazole after long term therapy. Lancet 1978 ; $\mathrm{i}: 214$.

8 Rotimi VO, Duerden BI, Ede V, Mackinnon AE: Metronidazole-resistant Bacteroides from untreated patient. Lancet 1979;i:833.

9 Hickey MM, Davies UM, Dave J, Vogler M, Wall R: Metronidazole-resistant Bacteroides fragilis infection of prosthetic hip joint. J Infect 1990;20:129-133.

10 Eme Me A, Acar JF, Goldstein FW: Bacteroides fragilis resistant to metronidazole. $\mathrm{J}$ Antimicrob Chemother 1983;12:523-524.
11 O'Donoghue MA, Potter J, Allen KD: Metronidazole-resistant Bacteroides fragilis wound infection. J Infect 1992;25:211-214.

12 Rotimi VO, Khoursheed M, Brazier JS, Jamal WY, Khodakhast FB: Bacteroides species highly resistant to metronidazole: An emerging clinical problem? Clin Microbiol Infect 1999;5: 166-169.

13 Bruce D, Bradley P: Metronidazole discs on anaerobic neomycin blood agar plates: An aid to diagnosis of anaerobic infection. Med Lab Sci 1977;34:273-275.

14 Edwards DI: Nitroimidazole drugs-action and resistance mechanisms. I. Mechanisms of action. J Antimicrob Chemother 1993;31:9-20.

15 Muller M: Reductive activation of nitroimidazoles in anaerobic micro-organisms. Biochem Pharmacol 1986;35:37-41.

16 Brazier JS, Hall V, Duerden BI: Artefactual resistance to metronidazole in anaerobes of Bacteroides fragilis group. J Antimicrob Chemother 1992;30:533-534.

17 Reysset G: Genetics of 5-nitroimidazole resistance in Bacteroides species. Anaerobe 1996;2: 59-69.

18 Haggoud A, Reysset G, Sebald M: Cloning of a Bacteroides fragilis chromosomal determinant coding for 5-nitroimidazole resistance. FEMS Microbiol Lett 1992;95:1-6.

19 Reysset G, Haggoud A, Su WJ, Sebald M: Genetics and molecular analysis of pIP417 and pIP419: Bacteroides plasmids encoding 5-nitroimidazole resistance. Plasmid 1992;27:181190.

20 Stubbs SL, Brazier JS, Talbot PR, Duerden BI: PCR-restriction fragment length polymorphism analysis for identification of Bacteroides spp and characterization of nitroimidazole resistance genes. J Clin Microbiol 2000;38:3209_ 3213.
21 Carlier J, Sellier N, Rager M, Reysset G: Metabolism of a 5-nitroimidazole in susceptible and resistant isogenic strains of Bacteroides fragilis. Antimicrob Agents Chemother 1997; 41:1495-1499.

22 Breuil J, Patey O, Dublanchet A, Burnat C: Plasmid and non-plasmid mediated reduced sensitivity to metronidazole in the Bacteroides fragilis group. Scand J Infect Dis 1990;22:247248.

23 Reysset G, Haggoud A, Sebald M: Genetics of resistance of Bacteroides species to 5-nitroimidazole. Clin Infect Dis 1993;16:S401-S403.

24 Breuil J, Dublanchet A, Truffaut N, Sebald M: Transferable resistance in the Bacteroides fragilis group. Plasmid 1989;21:151-154.

25 Breuil J, Burnat C, Patey O, Dublanchet A: Survey of Bacteroides fragilis susceptibility patterns in France. J Antimicrob Chemother 1989;24:69-75.

26 Trinh S, Reysset G: Detection by PCR of the nim genes encoding 5-nitroimidazole resistance in Bacteroides spp. J Clin Microbiol 1996;34:2078-2084.

27 Haggoud A, M'Hand RA, Reysset G, El M'Dagghri N, Benbachir M, Moumni M: Prevalence and characteristics of nim genes encoding 5-nitroimidazole resistance among Bacteroides strains isolated in Morocco. Microb Drug Resist 2001;7:177-181.

28 Lubbe MM, Stanley K, Chalkley LJ: Prevalence of nim genes in anaerobic/facultative anaerobic bacteria isolated in South Africa. FEMS Microbiol Lett 1999;172:79-83. 